\section{T. L. McMeekin}

Thomas Leroy MCMEeKIN, commonly known as "Mac" to his friends, died in Columbia, South Carolina on 11 November 1979. He did notable work in protein chemistry over more than three decades, first in academic research and later as the head of an important government laboratory.

Born on 8 May 1900 in Monticello, South Carolina, he took his $\mathrm{PhD}$ at the University of Chicago in 1925, under the direction of Professor F. C. Koch, his thesis dealing with the purification of pepsin. In 1928, he joined the Department of Physical Chemistry at Harvard Medical School, headed by Professor Edwin J. Cohn. Cohn, whose primary concern was with the physical chemistry of proteins, was then engaged in purifying the substance in liver that was active in the treatment of pernicious anemia. This program achieved a clinically effective liver extract, though it failed to overcome the formidable problem of isolating what was much later to be known as vitamin $B_{12}$ McMeekin played a central part in this work, but his major contribution during his twelve years at Harvard came in studies on the physical chemistry of amino acids, peptides, and a wide variety of related molecules.

This cooperative enterprise involved Cohn, J. P. Greenstein, myself and other members of the laboratory, together with George Scatchard and John G. Kirkwood at MIT, and Jeffries Wyman at the Harvard Biological Laboratories. McMeekin's role was primarily in the choice and synthesis of a wide variety of organic compounds, chosen to define the relations between structure and relative solubility in water and organic solvents, and other properties such as partial molal volumes. The aim was to provide a basis for interpreting the unusual properties of amino acids and peptides, and (by implication) of proteins, in terms of their content and arrangement of polar, nonpolar, and electrically charged groups. McMeekin's work was essential to all this; in particular his studies on the influence of non-polar groups on solubility in various media provided fundamental data and systematic relations for the understanding of what later came to be called hydrophobic interactions. In studies on proteins, he achieved the crystallization of two forms of albumin from horse serum.

In 1940 he joined the Eastern Regional Laboratory of the U.S. Department of Agriculture in Philadelphia, and later became director of its Protein Division. With R. C. Warner in 1942 he carried out a fundamental study on the hydration of ß-lactoglobulin crystals, showing for the first time that it was possible to study protein crystals by direct analysis of water, salt, and protein, and to relate the composition of the crystal to that of the surrounding medium. His studies on milk proteins notably on $\beta$-lactoglobulins and on the separation and characterization of several components of casein - led to his receiving the Borden Award in 1950. Other important contributions from his laboratory involved the preparation of new types of protein fibers and study of partial specific volumes of proteins in relation to their structure.

On retiring from the Protein Division in 1965 he became Research Professor of Biology at the University of South Carolina in Columbia until 1972. He spent his last years near by, in Monticello, his birthplace, remaining active and alert until his final brief illness.

He was twice married, first to the late Vera Crockatt, and subsequently to Crystal Stribling, who survives him. He had two daughters and a son by his first marriage. One daughter, Dorothy McMeekin, is Professor in the Department of Natural Science in Michigan State University at East Lansing.

McMeekin was modest and gentle in manner; but his strength of character was obvious to those who knew him. He was ever helpful to his colleagues and to younger co-workers. He had an excellent quiet sense of humour, and a shrewd eye for the strengths and weaknesses of other human beings. Above all he was a man of complete integrity, who will be remembered with admiration and affection, especially by that band of protein chemists of which he was a distinguished member.

John T. Edsall

\section{H. H. Plaskett}

WITH THE DEATH of Professor H. H. Plaskett on 26th January 1980, Britain has lost one of its most distinguished astronomers.

Harry Hemley Plaskett was born in 1893, the elder son of Dr J. S. Plaskett, who later became Director of the Dominion Astrophysical Observatory in Victoria, B.C. After service in France during the First World War, Plaskett joined his father's observatory as a staff member, where he remained for eight years until he became Professor of Astrophysics at Harvard in 1928. He was appointed Savilian Professor of Astronomy in Oxford in 1932, but his productive years were again interrupted by war service between 1939 and 1944. Part of the later years of the war were spent by him in developing a new type of sextant for the Ministry of Aircraft Production, which was in constant use until quite recently.

Almost the whole of Plaskett's working life was spent in astronomical spectroscopy, beginning during his years in Canada with steller spectroscopy and his pioneering work on the emission spectra of gaseous nebulae. He had always recognised the importance of solar studies as a basis for understanding stellar atmospheres, and remarked in 1931 that "spectroscopic investigations of the sun seem likely to yield more information about stellar physics than spectroscopic studies of the stars themselves"'. In this year he published his classical observations of the variation of the profiles of the $\mathrm{Mgb}$ lines across the solar disk. This was an important step forward in astrophysics which involved the development and application of new and accurate techniques of spectrophotometry, many of them devised by Plaskett himself especially for this study. It also came at an appropriate time because of parallel work on the theory of line formation in stellar atmospheres being conducted by Eddington and Milne, following earlier work by Schuster. Plaskett's comparison of theory and observation led to a first good understanding of the mechanisms by which stellar spectrum lines are formed.

On his appointment at Oxford, Plaskett decided to devote himself wholly to solar studies. To this end he built an advanced solar telescope with a high dispersion spectrograph at the observatory. With it he planned a series of observations of photospheric mass motion through the Doppler displacements of special lines. Although this work was soon stopped by the Second World War, he felt so much encouraged by its progress after the war that he built a second solar telescope of aperture 20 in and focal length $35 \mathrm{~m}$, complete with a fine spectrograph. With this he resumed his work on solar mass motions, the results of which, and their interpretation, were presented in a well known series of papers. During his 28 years in Oxford, Plaskett built up a small but distinguished group of solar astronomers, which was strengthened through close contacts with mathematicians and theoretical astronomers in other departments of the university. Over the years, many astronomers became indebted to him for the great help they received, and many owed the start of their careers to him.

Plaskett had a considerable influence on the development of astronomy in Britain. In a celebrated Presidential Address to the Royal Astronomical Society in 1946, he proposed the building of a large optical telescope in Britain. This resulted in the construction in 1968 of the 98 in Isaac Newton telescope at Herstmonceux, which is now soon to be moved to the new Northern Hemisphere Observatory in the Canary Islands.

After his retirement, Plaskett continued to work in the Department of Astrophysics and he worked regularly with the 20 in telescope until the age of 84 years. He was elected a Fellow of the Royal Society in 1936 and was awarded the Gold Medal of the Royal Astronomical Society in 1963. $\mathrm{He}$ is survived by his wife Edith, and his son and daughter.

D.E. Blackwell 